\title{
Adsorptive Interaction of Chiral Amino Acids on $\beta$-Cyclodextrin Bonded to Silica Particles
}

\author{
Abhijit Banik, Monali Dutta Saikia* \\ Department of Chemistry, Arya Vidyapeeth College, Guwahati, India \\ Email: "monalisaikia@hotmail.com
}

Received January 17, 2013; revised February 25, 2013; accepted March 3, 2013

\begin{abstract}
The adsorption of certain chiral amino acids from aqueous solution onto $\beta$-cyclodextrin silica particles (CDS) had been investigated with the aim of in-depth understanding of the host-guest interaction. The adsorption intensity was found to be strongly dependent on the aqueous phase $\mathrm{pH}$ and this dependence could be interpreted from a model for neutral species adsorption in all cases. Adsorption equilibrium data fitted well to the Freundlich isotherm. The adsorption efficiencies of L-amino acids were found to be higher compared to the corresponding D-isomers. Hydrogen bonding and hydrophocities of amino acids were responsible for the differences in adsorption, by influencing the strength of interactions between the amino acid and CDS. The adsorption rate curves for all the molecules appeared to be typical of the pseudo second-order kinetics. Infrared spectral analysis has been performed to characterize adsorptive interaction. The porous structure of CDS as revealed by scanning electron micrograph thus shown to be promising materials for enantioselective separation of amino acids. In addition, molecular modeling studies performed on such molecules were found to correlate very well to the experimental results obtained.
\end{abstract}

Keywords: Adsorption; Amino Acid; $\beta$-Cyclodextrin; Chiral; Molecular Modeling

\section{Introduction}

Chiral amino acids are one of the most important biomolecules because of their relevance in nature and their chemical richness. It is well known that in nature amino acids occur in L-forms and they play an important role in the food and pharmaceutical industries. It may be important to be able to detect the presence of D-amino acids in biological systems [1]. The amount of certain D-amino acids in various types of samples has been found to be of relevance for many aspects of biochemical and molecular biological research [2,3], in the control of food and beverages [4], as well as in age determination [5,6]. Therefore, chiral analysis of $\mathrm{D} / \mathrm{L}$-amino acids is of increasing importance in biological science. Various chiral separation methods are available for the enantiomeric resolution of amino acids. Methods based on chiral ligandexchange [7-10] and on the formation of inclusion complexes with cyclodextrins have received the most attention [11-13]. Cyclodextrins (CD) were employed in their native form or after modification by methylation, acetylation or by binding other structural moieties to the hydroxyl groups of the glucose [14-16]. The unique hostguest chemistry of CDs is highly conducive to the selective uptake of organic molecules from aqueous systems

*Corresponding author.
[17-20]. CDs themselves, are highly water soluble, and must therefore be processed into solid forms before they can be implemented into usable separation technology.

$\beta$-Cyclodextrin $(\beta$-CD) is a cyclic oligosaccharide with seven glucose units, with its cavity structure, and can form an inclusion complex with certain molecules through a host-guest interaction. The conical shape of $\beta$-CD molecule results in well-defined hydrophobic cavity with top and bottom diameters of 6.5 and $6.0 \AA$ that can accommodate the inclusion of various organic molecules with suitable geometry and function [21]. Figure 1 shows the chemical structure of $\beta$-CD. The chiral nature of the cavity in these molecules makes them useful for enantiomeric separation applications. Polymeric sorbents have been extensively tested for amino acid adsorption [22]. The $\beta$-CD polymer has been shown to be a good sorbent for amino acids in our previous study [23]. Tang et al. [24] have studied the application of cross-linked $\beta$-CD polymer for adsorption of aromatic amino acids.

In this paper, we report both experimental and theoretical results on adsorption behaviour of certain chiral amino acids on $\beta$-CD bonded to silica gel with emphasis on understanding the host-guest interaction and such a study will be useful for better understanding of the chiral recognition mechanism of amino acids by $\beta$-CD bonded silica gel as a selective sorbent. Also we have character- 


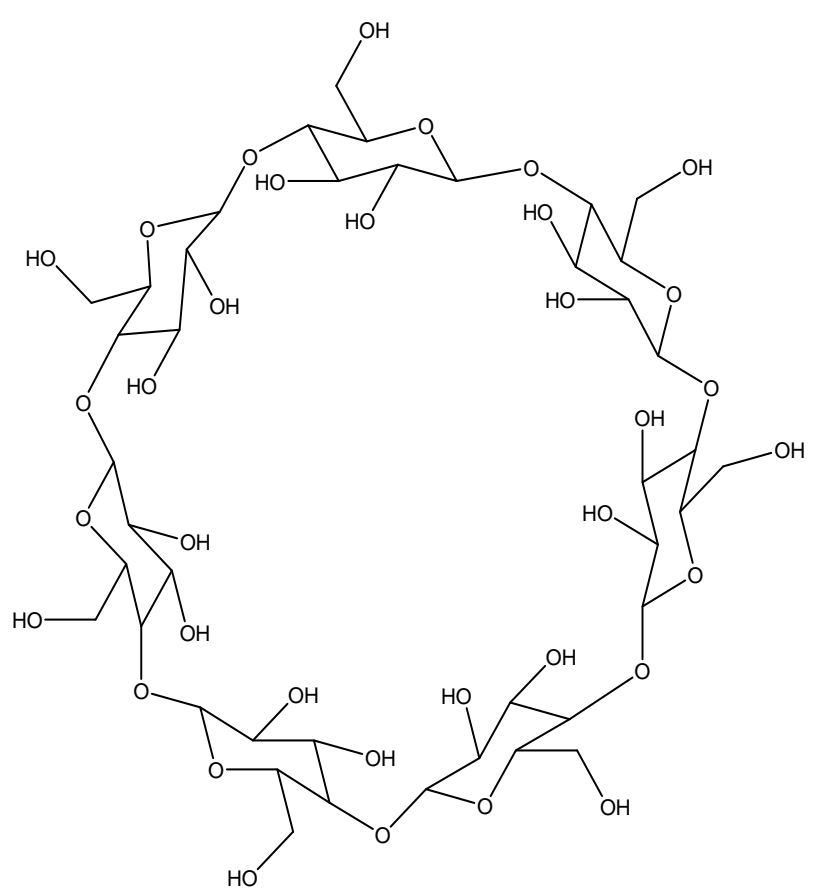

Figure 1. Molecular structure of $\beta$-cyclodextrin.

ized the amino acid- $\beta$-CD complex by UV-Visible (UVVis) spectroscopy.

\section{Experimental}

\subsection{Materials}

The amino acids used in this study namely D-phenylalanine, L-phenylalanine, D-tryptophan, L-tryptophan, Dtyrosine and L-tyrosine (guests) were obtained from Sigma-Aldrich Chemicals Pvt. Ltd., USA. $\beta$-CD was obtained from Hi Media Laboratories Pvt. Ltd., Mumbai, India. The silica gel of 60 - 120 mesh size was obtained from SRL Pvt. Ltd., Mumbai, India. We have chosen this particular silica gel because of its highly porous structure and appropriate physical and chemical properties to achieve both adequate loading capacity and high-binding capacities. Moreover, it is an efficient adsorbent for separation of organic compounds by chromatographic methods. 3-Glycidoxypropyltrimethoxysilane was also obtained from Sigma-Aldrich Chemicals Pvt. Ltd., USA. The other reagents used as buffer (sodium phosphate, sodium acetate, sodium carbonate and sodium chloride) were supplied by Qualigens, India (Mumbai) and were of analytical grade.

\subsection{Preparation of $\beta$-CD Bonded Silica Stationary Phase (CDS)}

CDs are highly soluble in water and so must be to some solid form before implementing them to adsorption technology. CD containing polymers are useful materials for selective adsorption or separation of organic compounds. For that reason, we have synthesized a polymer (i.e. CDS) as reported in our earlier work $[23,25]$ in which $\beta$-CD is bonded to silica particles. Briefly, 1.145 gm of $\beta$-CD was dissolved in $25 \mathrm{ml}$ of dry dimethyl formamide (DMF), to which $0.1 \mathrm{gm}$ of metal sodium was added. The reaction was allowed to occur with stirring at room temperature for about $30 \mathrm{~min}$. After filtration, 0.45 $\mathrm{ml}$ of 3-glycidoxypropyltrimethoxysilane was added to the filtrate, which was allowed to react at $90^{\circ} \mathrm{C}$ for $5 \mathrm{~h}$. Then, $5.0 \mathrm{gm}$ of silica gel was added, and the mixture was allowed to react for $10 \mathrm{~h}$ at $80^{\circ} \mathrm{C}-100^{\circ} \mathrm{C}$. The CDS was filtered, and washed with DMF, methanol, doubly distilled water and acetone in sequence. Subsequently, the $\mathrm{CDS}$ was dried at $120^{\circ} \mathrm{C}$ for $3 \mathrm{~h}$, and kept in a desiccator before use.

\subsection{Equilibrium Isotherms and Adsorption Rate}

Equilibrium isotherms were obtained by contacting $25 \mathrm{ml}$ of aqueous amino acid solution with different amounts of $\mathrm{CDS}$ in a thermostated shaker bath controlled at $25^{\circ} \mathrm{C} \pm$ $0.5^{\circ} \mathrm{C}$. The $\mathrm{pH}$ of the solution was varied between 3 and 9 using appropriate dose of buffer. The initial concentration of amino acid in the aqueous solution was varied between 5 and $10 \mathrm{mM}$. The equilibration time was $8-10$ h. After equilibrium was achieved, the mixture was allowed to settle and the supernatant liquor was filtered to remove any particulate matter. The clear solution thus obtained was analyzed by means of a UV-Vis spectrophotometer (Lambda $25 \mathrm{UV} / \mathrm{Vis}$, Perkin Elmer) calibrated at the wavelength of maximum absorbance $\left(\lambda_{\max }\right)$ of the specific amino acid enantiomer. For quantitative spectrophotometric analysis, standard calibration curves of different amino acid enantiomers were prepared at their $\lambda_{\max }$ values such as $289 \mathrm{~nm}$ for D- and L-phenylalanine; $288 \mathrm{~nm}$ for D- and L-tryptophan and $285 \mathrm{~nm}$ for D- and L-tyrosine. For the purpose of estimation $0.2 \mathrm{ml}$ of the supernatant liquor was drawn with glass syringe and diluted with the buffer used for preparing the amino acids solution. Absorbance was measured in the spectrophotometer and the concentration was determined from calibration curve. The amount of amino acid per gram of CDS " $q$ " (mmol $\left.\cdot \mathrm{g}^{-1}\right)$ was calculated as $q=V \Delta C / W$ where, $\Delta C$ is the change in solute concentration ( $\left.\mathrm{mmol} \cdot \mathrm{l}^{-1}\right), V$ is the solution volume (1) and $W$ is the weight of adsorbent (g).

Experiments on adsorption rate were conducted in a stirred constant volume vessel similar to that used in our previous work [26]. The liquid volume was $100 \mathrm{~cm}^{3}$ with 3 - 3.5 gm of CDS sample. The initial concentration of amino acid was taken between 10 and $15 \mathrm{mM}$ at $25^{\circ} \mathrm{C} \pm$ $0.5^{\circ} \mathrm{C}$. The liquid volume was monitored at equal time intervals till equilibration. 


\subsection{UV-Vis Spectroscopy}

The UV-Vis spectra were recorded with a Varian Cary 50 Bio (Sweden) UV-Vis spectrophotometer using quartz cells, between 200 and $400 \mathrm{~nm}$. In the experiments of guests with $\beta$-CD (host), the concentration of the host was varied from $1 \times 10^{-3} \mathrm{M}$ to $12 \times 10^{-3} \mathrm{M}$ while the concentration of the guest was kept constant at $2 \times 10^{-3}$ $\mathrm{M}$. The mixtures were stirred at $25^{\circ} \mathrm{C}$ at a speed of 280 $\mathrm{rpm}$ for $4 \mathrm{~h}$ and the supernatant was analysed by UV-Vis spectrophotometer.

\subsection{Instrumental Studies}

FT-IR spectra were obtained by the $\mathrm{KBr}$ method using PerkinElmer, model Spectrum One. Morphological features of samples were obtained with a LEO 1430 VP Scanning Electron Microscope.

\subsection{Molecular Modeling Studies}

The inclusion process involving the guests and host $(\beta$-CD) was investigated by using the Parametric Model 3 (PM3) quantum-mechanical semiempirical method. All theoretical calculations were performed using GAUSSIAN 09 software package [27]. For all the systems, a full geometry optimization was done at the PM3 level. Using standard bond lengths as the initial input, the carbon chains or rings in the guest molecule was vertically inserted into the cavity of the hosts along the middle axis from the large rim of hosts in CHEM 3D. Stabilization energy $(\Delta \mathrm{E})$ upon complexation between guests and the host were calculated for the minimum energy structure according to Equation (1) [28]

$$
\Delta \mathrm{E}=\mathrm{E}_{\text {complex }}-\left(\mathrm{E}_{\text {guest }}+\mathrm{E}_{\text {host }}\right)
$$

where $\mathrm{E}_{\text {complex }}, \mathrm{E}_{\text {guest }}$ and $\mathrm{E}_{\text {host }}$ represent $\mathrm{HF}$ energies (heats of formation) of the complex, the free amino acid and the host, respectively.

\section{Results and Discussion}

\subsection{Adsorption of Amino Acids onto CDS}

The amino acids studied have molecular structures and $\mathrm{pKa}$ valiues shown in Figure 2. The molecular volume and weight of the above enantiomers calculated using Alchemy 2000 software are given in Table 1. The adsorption isotherms of the above mentioned molecules are shown in Figures 3(a) and (b). It could be seen from Figure 3 that the adsorption of the amino acids on CDS increased in the following order: D-tyrosine $<$ L-tyrosine $<$ D-phenylalanine $<$ L-phenylalanine $<$ D-tryptophan $<$ L-tryptophan. The $\mathrm{pH}$ dependence of the adsorption is of importance as the $\mathrm{pH}$ determines the extent of ionisation of the amino acid molecules, thereby affecting the ad-
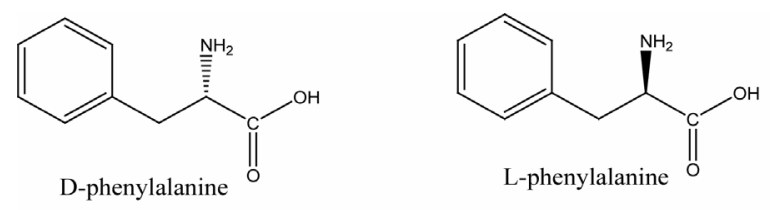

$$
\mathrm{pKa}_{1}=2.20 ; \mathrm{pKa}_{2}=9.31
$$<smiles>N[C@@H](Cc1c[nH]c2ccccc12)C(=O)O</smiles>

D-tryptophan

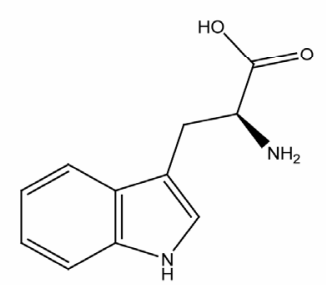

L-tryptophan

$\mathrm{pKa}_{1}=2.46 ; \mathrm{pKa}_{2}=9.41$<smiles>N[C@@H](Cc1ccc(O)cc1)C(=O)O</smiles>

D-tyrosine<smiles>N[C@@H](Cc1ccc(O)cc1)C(=O)O</smiles>

L-tyrosine

$\mathrm{pKa}_{1}=2.20 ; \mathrm{pKa}_{2}=9.20$

Figure 2. Structures of the amino acids studied.

Table 1. Properties of amino acids studied.

\begin{tabular}{ccc}
\hline Amino & $\begin{array}{c}\text { Molecular volume } \\
\left(\mathrm{cm}^{3} / \mathrm{mol}\right)(\mathrm{g})\end{array}$ & Molecular weight acid \\
\hline L-tryptophan & 173.30 & 196.16 \\
D-tryptophan & 170.92 & 157.12 \\
L-phenylalanine & 139.83 & 174.13 \\
D-phenylalanine & 141.13 & \\
L-tyrosine & 153.93 & \\
D-tyrosine & 154.82 & \\
\hline
\end{tabular}

sorption affinity. The $\mathrm{pH}$ dependence could be interpreted by considering the adsorption affinity, expressed as the slope of the linear region of the isotherm $\left(q / C_{e}\right)$.

Table 2 shows the variation of $q / C_{e}$ with $\mathrm{pH}$ and inferred a strong relationship, the affinity being considerably low at high $\mathrm{pH}$ under which the amino acids exist in dissociated forms. The behaviour was akin to that observed in the case adsorption of the beta-lactams on polymeric resins and activated carbon [29]. Since the concentration of neutral form of the amino acid $\left(C_{n}\right)$ was related to $\mathrm{pH}$ and the total concentration by HendersenHasselbach relationship [30]:

$$
C_{n}=\frac{C_{e}}{1+10^{p H-p K a_{1}}}
$$

the isotherms, as shown in Figure 4 appeared to follow a 


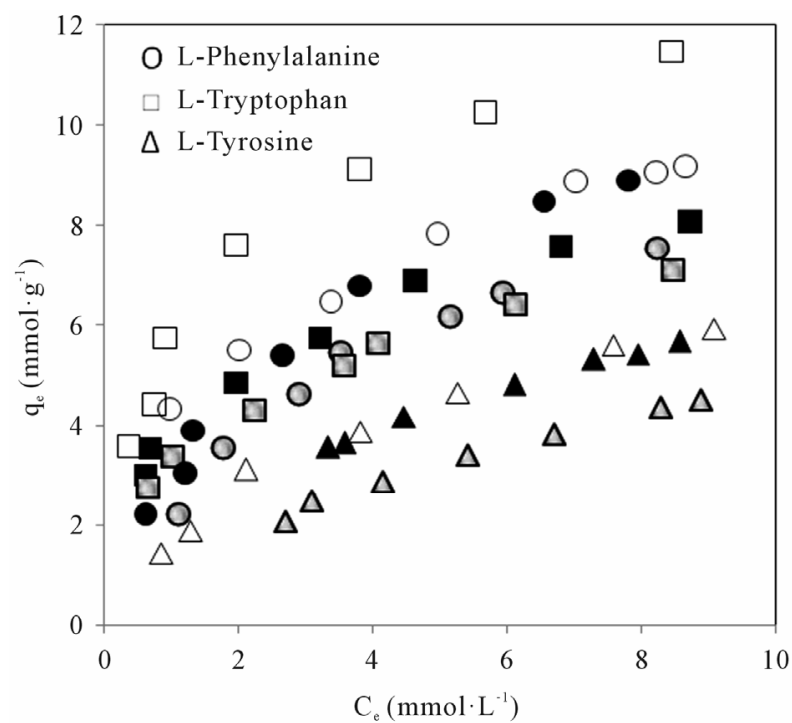

(a)

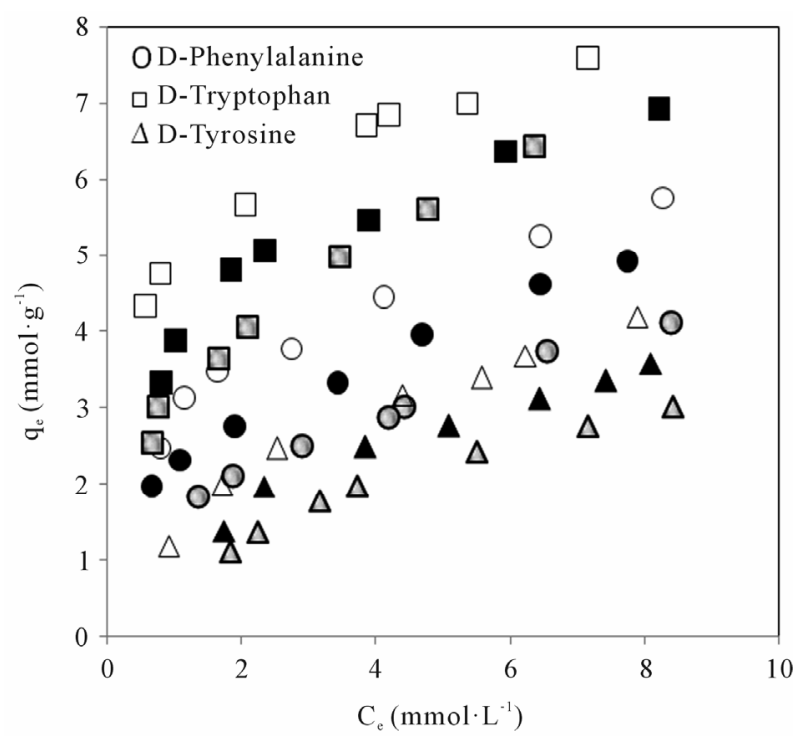

(b)

Figure 3. (a) Adsorption isotherms of the L-amino acids in CDS at different pH of aqueous phase. Open, closed and shaded symbols for $\mathrm{pH} \mathrm{3,7}$ and 9 respectively; (b) Adsorption isotherms of the D-amino acids in CDS at different pH of aqueous phase. Open, closed and shaded symbols for $\mathbf{p H}$ 3,7 and 9 respectively.

model for neutral species adsorption and can well represent the $\mathrm{pH}$ variation.

The $\mathrm{pH}$ dependence of the affinity is more important, in that neutral form of the amino acids could be considered to have a high adsorption affinity. The reduction in adsorption capacity of various amino acids with increase of $\mathrm{pH}$ had been interpreted from a model incorporating hydronium ion concentration and dissociation constant [31] attributable to both the carboxylic and amino functional groups. At low $\mathrm{pH}$, the amino acids are markedly

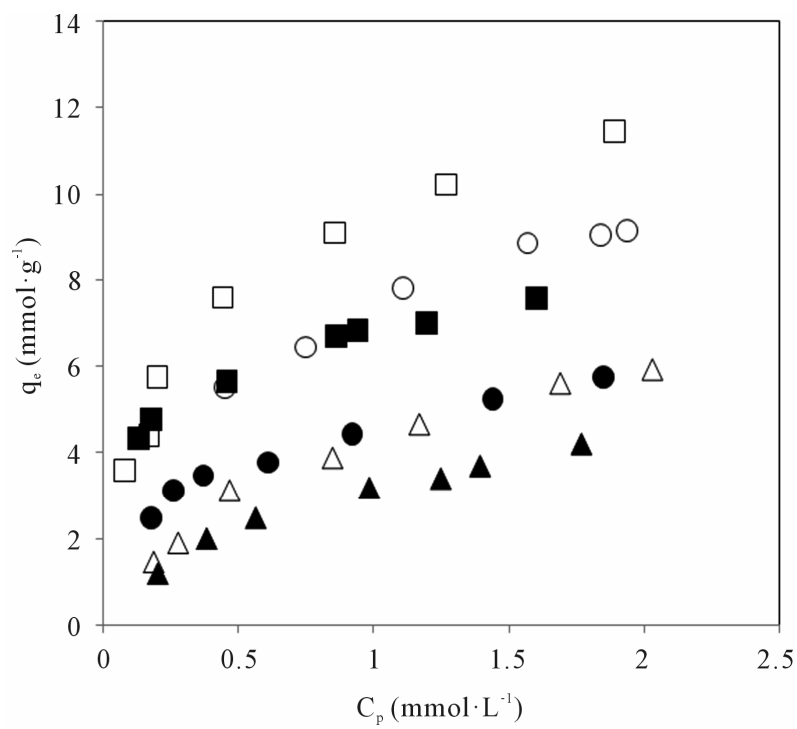

Figure 4. Dependence of adsorption on the concentration of the neutral form of amino acids in CDS. Open and closed symbols for $\mathrm{L}$ - and $\mathrm{D}$-series respectively.

Table 2. Adsorption affinity of amino acids at different $\mathrm{pH}$ values on CDS.

\begin{tabular}{|c|c|c|c|}
\hline Amino acids & $\mathrm{pH}$ & $\begin{array}{c}\text { Adsorption } \\
\text { affinity } q / C_{e}\left(\mathrm{Lg}^{-1}\right)\end{array}$ & $\begin{array}{l}\text { Interaction energy } \\
(\Delta \mathrm{E})\left(\mathrm{KJ} \cdot \mathrm{mol}^{-1}\right)\end{array}$ \\
\hline \multirow{3}{*}{ L-tryptophan } & 3 & 10.011 & \multirow{3}{*}{-52.51} \\
\hline & 7 & 4.939 & \\
\hline & 9 & 4.174 & \\
\hline \multirow{3}{*}{ D-tryptophan } & 3 & 7.322 & \multirow{3}{*}{-49.88} \\
\hline & 7 & 4.031 & \\
\hline & 9 & 3.681 & \\
\hline \multirow{3}{*}{ L-phenylalanine } & 3 & 4.317 & \multirow{3}{*}{-47.25} \\
\hline & 7 & 3.599 & \\
\hline & 9 & 1.986 & \\
\hline \multirow{3}{*}{ D-phenylalanine } & 3 & 3.131 & \multirow{3}{*}{-44.63} \\
\hline & 7 & 2.925 & \\
\hline & 9 & 1.343 & \\
\hline \multirow{3}{*}{ L-tyrosine } & 3 & 1.845 & \multirow{3}{*}{-44.63} \\
\hline & 7 & 1.071 & \\
\hline & 9 & 0.767 & \\
\hline \multirow{3}{*}{ D-tyrosine } & 3 & 1.282 & \multirow{3}{*}{-39.38} \\
\hline & 7 & 0.788 & \\
\hline & 9 & 0.600 & \\
\hline
\end{tabular}


hydrophobic and the hydrophobic interaction of the undissociated amino acids would be greater than the corresponding ionic form that exist at high $\mathrm{pH}$. Thus, the observation of high $q / C_{e}$ at low $\mathrm{pH}$ implied the probable role of hydrophobic interaction.

Estimated on the basis of the proposed hydrophobicity scale [32], the hydrophobicity of the beta-lactams was found to increase in the same order: L-tyrosine $<\mathrm{L}-$ tryptophan $<$ L-phenylalanine. Thus, the relative difference in adsorption affinity could not be explained only on the basis of hydrophobicity of amino acids as L-tryptophan showing higher adsorption is less hydrophobic compared to L-phenylalanine. The difference in adsorption may perhaps be explained on the basis of the formation of the hydrogen bonded network and the suitability in space between the host and guest molecules (i.e. the amino acids and CDS).The adsorption of L-enantiomers are higher than their corresponding D-forms. This difference in adsorption behaviour of CDS for the enantiomeric species may be due to the number and types of hydrogen bond formed as well as the extent of penetration of amino acids to the torous cavity during the formation of surface supramolecular complex. CD has the chiral binding microenvironment formed by many chiral atoms. That is why $\beta$-CD can bind chiral enantiomers. Such inference will further be clear from the discussion on molecular modelling, Fourier Transform Infrared (FTIR) and UV spectroscopic studies to follow.

Freundlich isotherm (Equation (3)) was used to describe equilibrium adsorption data, because different energy adsorption sites are expected in the polymeric network [33].

$$
q_{e}=K_{f} C_{e}^{n}
$$

where $K_{f}$ is the Freundlich constant, $\mathrm{Lg}^{-1}$; and $1 / n$ is the Freundlich constant characteristic of adsorption intensity. The fitting parameters for the Freundlich isotherm by non-linear regression analysis are shown in Table 3. The Freundlich isotherm was found to be consistent for adsorption of amino acids on cross-linked $\beta$-CD polymer [24].

Adsorption rate curve for amino acids on CDS were generated at a stirring speed of $800 \mathrm{rpm}$ as shown in Figure 5. Mathematical models of pseudo-first by Lagergren and pseudo-second by Ho-McKay [34] reaction orders have been used to describe kinetic process of physical adsorption of aromatic acids (Table 4). The values of rate constants calculated from the linear plots of pseudo-first and pseudo-second kinetic equations shown in Table 5. It can be seen from Table 5 that the sorption of amino acids is more consistent with kinetic model of pseudo-second order: the correlation coefficient values for pseudo-second order equation are greater than for pseudo-first order one.
Table 3. The values of parameters of the Freundlich adsorption isotherms for amino acids on CDS at $25^{\circ} \mathrm{C}$.

\begin{tabular}{|c|c|c|c|c|}
\hline Amino acids & $\mathrm{pH}$ & $K_{f}$ & $1 / n$ & $\begin{array}{c}\text { Correlation } \\
\text { coefficient }\left(\mathrm{R}^{2}\right)\end{array}$ \\
\hline \multirow{3}{*}{ L-tryptophan } & 3 & 5.551 & 0.2844 & 0.9900 \\
\hline & 5 & 3.871 & 0.2876 & 0.9958 \\
\hline & 7 & 3.288 & 0.2738 & 0.9983 \\
\hline \multirow{3}{*}{ D-tryptophan } & 3 & 4.413 & 0.2020 & 0.9920 \\
\hline & 5 & 3.957 & 0.3789 & 0.9753 \\
\hline & 7 & 3.122 & 0.2570 & 0.9903 \\
\hline \multirow{3}{*}{ L-phenylalanine } & 3 & 4.318 & 0.2812 & 0.9963 \\
\hline & 5 & 3.151 & 0.1913 & 0.9921 \\
\hline & 7 & 2.600 & 0.1916 & 0.9857 \\
\hline \multirow{3}{*}{ D-phenylalanine } & 3 & 2.810 & 0.2730 & 0.9969 \\
\hline & 5 & 1.853 & 0.2403 & 0.9942 \\
\hline & 7 & 1.510 & 0.3087 & 0.9941 \\
\hline \multirow{3}{*}{ L-tyrosine } & 3 & 1.845 & 0.1839 & 0.9920 \\
\hline & 5 & 2.285 & 0.2472 & 0.9957 \\
\hline & 7 & 1.257 & 0.2656 & 0.9930 \\
\hline \multirow{3}{*}{ D-tyrosine } & 3 & 1.442 & 0.1940 & 0.9934 \\
\hline & 5 & 1.160 & 0.1868 & 0.9906 \\
\hline & 7 & 1.020 & 0.1149 & 0.9934 \\
\hline
\end{tabular}

Table 4. Adsorption kinetic models and their linear forms.

\begin{tabular}{ccc}
\hline $\begin{array}{c}\text { Adsorption } \\
\text { reaction } \\
\text { models }\end{array}$ & Equation & Linear from \\
\hline Lagergren & $\log \left(\frac{q_{e}}{q_{e}-q_{t}}\right)=\frac{K_{1}}{2.303} t$ & $\log \left(q_{e}-q_{t}\right)=\log q_{e}-\frac{K_{1}}{2.303} t$ \\
Ho-McKay & $\frac{1}{\left(q_{e}-q_{t}\right)}=\frac{1}{q_{e}}+K_{2} t$ & $\frac{t}{q_{t}}=\frac{1}{K_{2} q_{e}^{2}}+\frac{1}{q_{e}} t$
\end{tabular}

Table 5. Adsorption parameters and correlation coefficient of kinetic models.

\begin{tabular}{ccccc}
\hline Amino acids & $\mathrm{K}_{1}\left(\mathrm{~s}^{-1}\right)$ & $\mathrm{R}^{2}$ & $\begin{array}{c}\mathrm{K}_{2} \\
\left(\mathrm{gmmol} \cdot \mathrm{s}^{-1}\right)\end{array}$ & $\mathrm{R}^{2}$ \\
\hline L-tryptophan & 0.389 & 0.895 & 1.811 & 0.995 \\
D-tryptophan & 0.587 & 0.960 & 3.119 & 0.983 \\
L-phenylalanine & 0.278 & 0.987 & 2.079 & 0.991 \\
D-phenylalanine & 0.631 & 0.924 & 1.936 & 0.943 \\
L-tyrosine & 0.686 & 0.879 & 1.028 & 0.907 \\
D-tyrosine & 0.601 & 0.893 & 1.037 & 0.901 \\
\hline
\end{tabular}




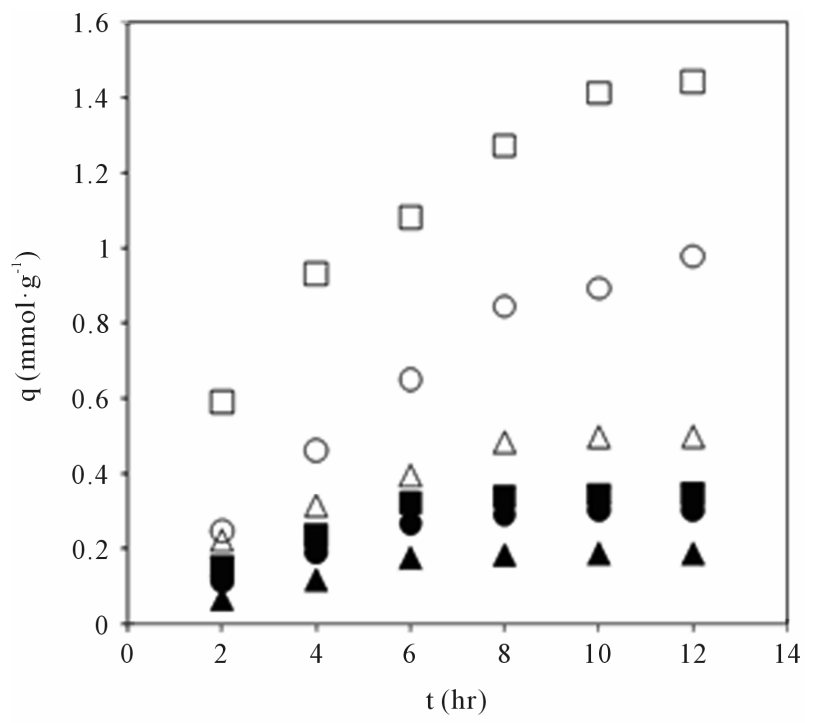

Figure 5. Adsorption rate curves for amino acids in CDS. Open and closed symbols for $\mathrm{L}$ - and $\mathrm{D}$-series respectively.

\subsection{UV-Vis Spectroscopic Studies}

$\mathrm{UV}-\mathrm{V}$ is spectrophotometric studies on the interactions of guests with host enabled the determination of stability constants of inclusion complexes when their formation gave rise to appreciable spectral changes. Upon addition of host, to the guests absorptivity increased in each case and the increase was significant with higher added concentration. The wavelength corresponding to maximum of absorbance $\left(\lambda_{\max }\right)$ of free amino acids and their corresponding changes upon complexation with $\beta$-CD are listed in the Table 6.

The shifts towards lower wavelength in the spectra of the complexes may be attributable to the formation of hydrogen bonds. Because hydrogen bonding lowers the energy of " $n$ " orbitals, a hypsochromic shift (blue shift) was observed. L-phenylalanine- $\beta$-CD complex showed blue shift whereas no prominent changes were observed in case of D-phenylalanine. The blue shift was found to be significant in case of L-tryptophan- $\beta$-CD complex whereas D-tryptophan did not show any such changes. The L-tyrosine- $\beta$-CD complex showed blue shift but red shift have been noticed in case of D-tyrosine- $\beta$-CD complex. Thus, $\beta$-CD was found to be suitable as complexing agent for all the three chiral aromatic amino acids but formed greater number of hydrogen bonds with L-amino acids compared to D-amino acids, which will be more clear from molecular modelling studies performed on such complexes. The lack of selectivity towards phenylalanine may be due to lower number of hydrogen bonding sites in this molecule compared to the other two amino acids. Though UV-spectrometry is not conclusive to determine selectivity but from the changes we can infer that $\beta$-CD and its derivatives may be hopeful for chiral enan- tiomeric separation of molecules like tryptophan and tyrosine (see Figure S1 in the Appendix).

\subsection{Determination of Formation Constants of the Inclusion Complexes of Host with Guests}

The determination of formation constants $(K)$ of the host to the guests were realized by UV-Vis spectroscopy titration experiments. The $K$ values were calculated by applying least-squares fit to the plots of ([host][guest])/ $\Delta A$ versus ([host] + [guest]), according to the modified Benesi-Hildebrand Equation (4) [35,36]:

$$
\frac{[\text { host }][\text { guest }]}{\Delta A}=\frac{1}{K \Delta \epsilon}+\frac{1}{\Delta \epsilon}([\text { host }]+[\text { guest }])
$$

where, [guest] and [host] are the equilibrium concentrations of guest and hosts, respectively. $\Delta \epsilon$ is the difference between the extinction coefficients of free and complexed guest. $\triangle A$ is the difference between the absorbances of free and complexed guest at the same wavelength. Figure 6 shows the plots of ([host][guest])/ $\Delta A$

Table 6. $\lambda_{\max }$ values for free amino acids and their complexes.

\begin{tabular}{ccc}
\hline Guests & $\lambda_{\max }(\mathrm{nm})$ & $\begin{array}{c}\lambda_{\max }(\mathrm{nm}) \text { (upon complexation } \\
\text { of the guest with } \beta \text {-CD) }\end{array}$ \\
\hline L-phenylalanine & 211 & $196-206(\mathrm{bs})^{*}$ \\
D-phenylalanine & 208 & $208-211$ \\
L-tryptophan & $220,280,287$ & $200-206,253-258(\mathrm{bs})$ \\
D-tryptophan & 280,287 & $280-285,285-288$ \\
L-tyrosine & $202,211,270,277$ & $200-206,251-261(\mathrm{bs})$ \\
D-tyrosine & $200,222,274$ & $222-225,280-282(\mathrm{rs})^{* *}$ \\
\hline
\end{tabular}

*Blue shift; ${ }^{* *}$ Red shift.

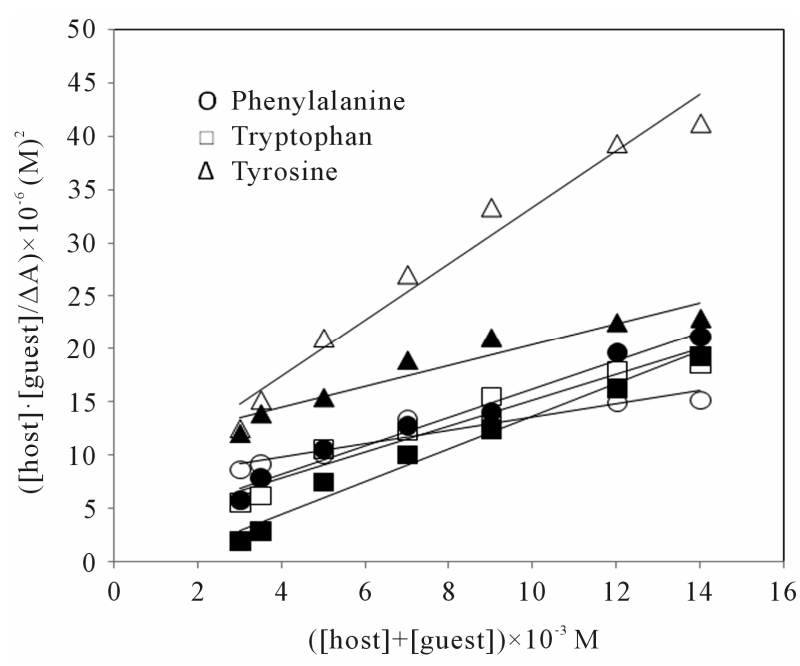

Figure 6. Plot of ([host][guest $] / \Delta \mathrm{A}$ vs ([host] + [guest]). Open and closed symbols for $L$ - and $D$-series respectively. 
versus ([host] + [guest]). The initial concentration of amino acids were kept at $2.0 \times 10^{-3} \mathrm{M}$, while the concentrations of the host were in the range from 1 to $12 \times 10^{-3}$ M. A linear least-square fitted to the plots. The $K$ values of inclusion complexes of host with guests were determined from the slopes and intercepts of the linear plots based on the Equation (4). The calculated $K$ values of the inclusion complexes are summarized in Table 7. For all the four inclusion systems, the dependencies were linear in the investigated concentration range, confirming that the stoichiometries of the inclusion complexes in solution were $1: 1[37,38]$.

For the amino acids studied, the changes in $K$ values reflected the same order as adsorption affinity, which suggests that the equilibrium of adsorption is a strong function of the strength of the solute-sorbent binding interaction. It is now apparent that the observed differences in adsorption affinity for various amino acids on CDS cannot be merely explained on the basis of hydrophobicity.

\subsection{Characterisation of Unloaded and Amino Acids/CDS Loaded Adsorbent}

\subsubsection{FTIR Spectroscopic Studies}

FTIR analysis permits spectrophotometric observation of the adsorbent surface in the range $450-4000 \mathrm{~cm}^{-1}$, and serves as a direct means for identification of the functional groups on the surface. An examination of the adsorbent surface after adsorption reaction possibly provides information regarding the surface groups that might have participated in the adsorption reaction and also indicates the surface sites on which adsorption has taken place.

The FTIR spectra of polymer showed a characteristic absorption band at $3481 \mathrm{~cm}^{-1}$ due to $\mathrm{O}-\mathrm{H}$ stretching vibration. The absorption peak at $1645 \mathrm{~cm}^{-1}$ possibly due to the presence of hydroxyl groups that were part of an aromatic system; vibration bands of $\mathrm{O}-\mathrm{H}$ were also visible at $1088 \mathrm{~cm}^{-1}$. Upon adsorption of amino acids on CDS the characteristics absorption peaks have been shifted from their position indicating interactions of the

Table 7. Calculated $K$ values of the complexes.

\begin{tabular}{ccc}
\hline Complex & $K$ in $(\mathrm{M})$ & $\mathrm{R}^{2}$ \\
\hline L-tryptophan- $\beta$-CD & 6.076 & 0.983 \\
D-tryptophan- $\beta$-CD & 4.435 & 0.978 \\
L-phenylalanine- $\beta$-CD & 2.496 & 0.948 \\
D-phenylalanine- $\beta$-CD & 1.551 & 0.977 \\
L-tyrosine- $\beta$-CD & 1.138 & 0.989 \\
D-tyrosine- $\beta$-CD & 1.087 & 0.828 \\
\hline
\end{tabular}

amino acid molecules with silica-bonded surface of $\beta$-CD molecules. The adsorption complexes showed a lowering of frequency of the $\mathrm{O}-\mathrm{H}$ stretching vibration thereby confirming complexation through hydrogen bonding and the lowering have been found more in case of complexes of L-amino acid molecules compared to that of D-amino acid molecules which may be due to stronger hydrogen bonding of L-series of molecules. In case of D-tyrosine, complexation caused a slight increase in O-H stretching frequency which is possibly due to cleavage of hydrogen bonding during complexation. Additionally, disappearance of N-H peak in any of the complexes clearly demonstrated complexation (see Figures $\mathbf{S 2}$ and $\mathbf{S 3}$ in the Appendix).

\subsubsection{Scanning Electron Micrographic (SEM) Study} The scanning electron micrographs for the CDS, Ltryptophan and L-phenylalanine adsorbed on CDS are presented in Figure 7. SEM analysis of polymer showed aggregates of irregularly shaped polycrystalline samples (Figure 7(a)) and the SEM of internal structure of the CDS (Figure 7(b)) showed porous structure which should significantly increase the available surface area of the CDS and, therefore, increase the adsorption capacity. L-tryptophan-CDS complex (Figure 7(c)) showed polycrystalline structures in which some threadlike structures have been found to be embedded onto the polymer surface and that of L-phenylalanine-CDS complex (Figure 7(d)) different from the morphology of the polymer indicating adsorption of amino acid molecules onto the porous surface of CDS.

\subsection{Molecular Modeling Studies}

Intensive theoretical works have been performed over the past few years on CDs owing to their conformational flexibility and large size. Parametric Model 3 (PM3) has been chosen to study host-guest complexes between $\beta$-CD and three important chiral amino acid molecules: phenylalanine, tryptophan and tyrosine. Due to the molecular size, PM3 is a powerful technique which can be currently applied and performs better than Austin model 1 (AM1) in biochemical systems due to its improved description of the interactions between non bonded atoms, e.g. hydrogen bond and steric effects [39]. The PM3 optimized structures of these complexes are schematically illustrated in Figure 8.

L-phenylalanine, D-phenylalanine, L-tyrosine, D-tyrosine and L-tryptophan all were found to enter through the narrower rim of the CD cavity whereas D-tryptophan entered to the cavity through the wider rim during complexation and stronger hydrogen bonding interactions had been found in case of tyrosine- $\beta$-CD, and tryptophan- $\beta$-CD complex compared to phenylalanine- $\beta$-CD complex. L-amino acids were found to penetrate more to 


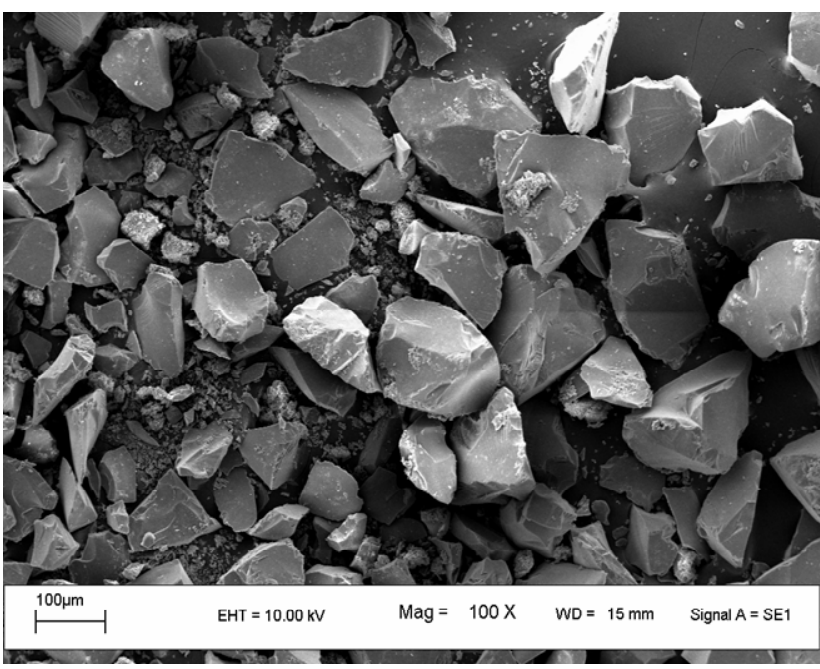

(a)

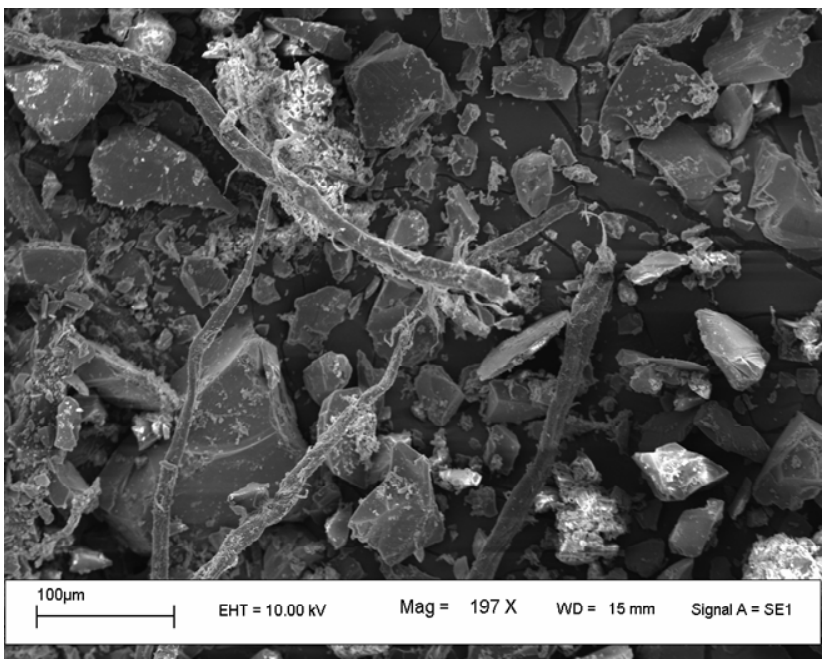

(c)

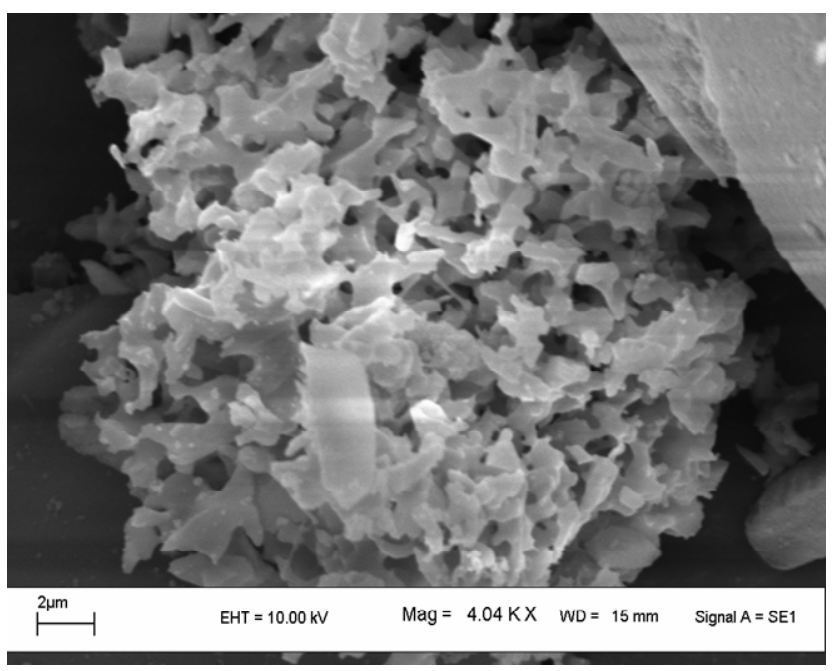

(b)

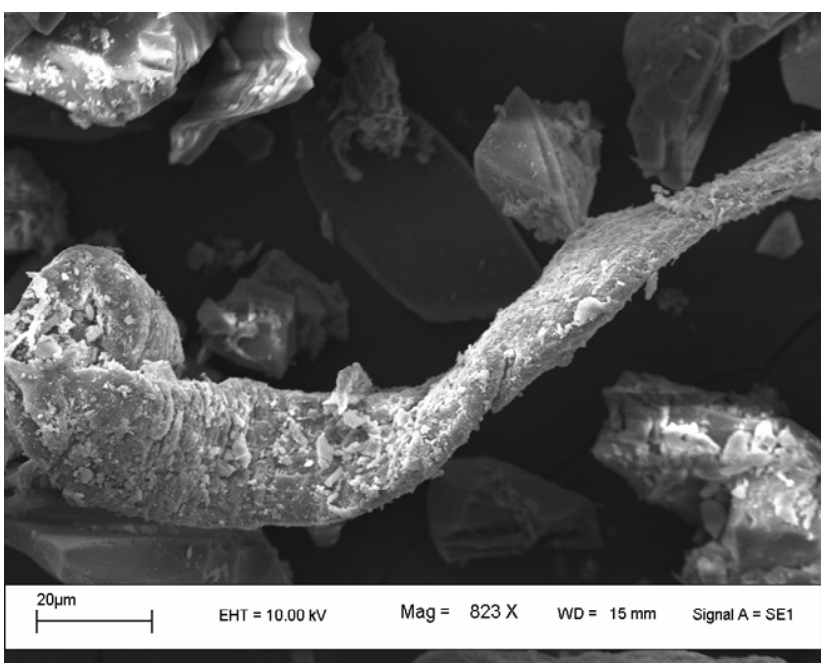

(d)

Figure 7. Scanning electron micrographs for (a) CDS; (b) Internal structure of CDS; (c) L-tryptophan-CDS complex and (d) L-phenylalanine-CDS complex.

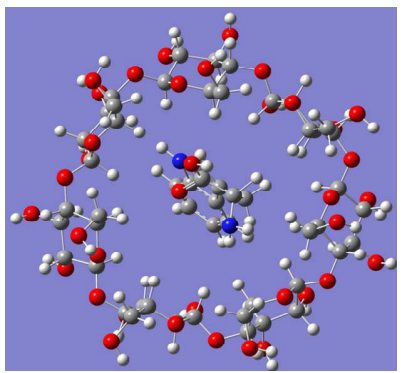

(a)

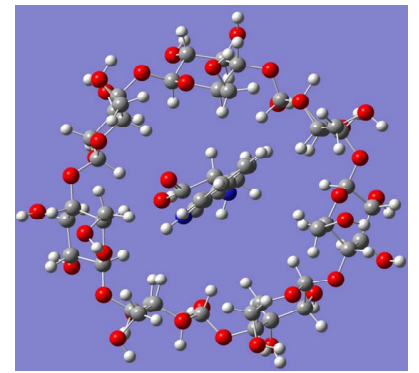

(b)

Figure 8. Optimised structures computed for (a) L-tryptophan- $\beta$-CD complex and (b) D-tryptophan- $\beta$-CD complex.

the cavity of the CD molecule compared to its D-enantiomer thereby enhancing the interaction sites to come in a suitable position for interaction. Hydrogen bonding and hydrophobic interactions were found to play a significant

role in stabilising all these supramolecular assemblies and the hydrophobic interactions were found to be more prominent in case of complexes of tryptophan and phenylalanine molecules thereby giving most stable interaction with tryptophan molecules. On the basis of quantum-mechanical semi-empirical PM3 studies it was observed that $\beta$-CD showed complexation with all the three chiral amino acids studied and the stabilization of the complexes as obtained by calculating stabilization energy values (Table 2) were found to increase in the same order as adsorption affinity. From Table 2, it can also be inferred that the chiral amino acid which shows highest affinity, also shows the highest stabilization energy. This inference may also be considered reasonable as L-series amino acids were found to penetrate more to the cavity of the CD molecule compared to its D-enantiomer thereby enhancing the interaction sites to come in 
a more suitable position for interaction.

\section{Conclusion}

The results of the investigation revealed some important insights for the adsorption mechanism of certain amino acid enantiomers on $\beta$-CD bonded to silica particles. The adsorption equilibrium may well characterized by the Freundlich isotherm. The rates of adsorption appeared to follow pseudo second order model under the experimental conditions used in the study. The adsorption intensity was strongly dependent on the aqueous phase $\mathrm{pH}$ and this dependence was typical of the behaviour predicted by a neutral species for all the amino acids on CDS. Adsorption of amino acids on CDS increased in the following order: tyrosine $<$ phenylalanine $<$ tryptophan. Hydrophobicity as well as hydrogen bonding interactions were mainly responsible for such differences in adsorption. Spectroscopic and theoretical studies supported such interactions and indicated that $\beta$-CD can bind the amino acids to form supramolecular complexes. Separation of chiral amino acids using CDS depended on the formation of an inclusion complex which was due to the hydrophobic effect, hydrogen bonding interactions between the molecule and secondary hydroxyl groups of the $\beta$-CD. This work further suggests that the host-guest interaction which can be postulated from the chemistry of binding mechanism may be used to adsorb amino acid enantiomers selectively onto CDS.

\section{Acknowledgements}

The authors gratefully acknowledge the award of a research Project under FAST TRACK SCHEME from Department of Science and Technology, New Delhi.

\section{REFERENCES}

[1] D. W. Armstrong, J. M. Duncan and S. H. Lee, "Evaluation of D-Ammino Acid Levels in Human Urine and in Commercial L-Amino Samples," Journal of Amino Acids, Vol. 95, No. 1, 1991, pp. 97-106.

[2] G. C. Barret, "Chemistry and Biochemistry of Amino Acids," Chapman and Hall, New York, 1985. doi:10.1007/978-94-009-4832-7

[3] K. H. Schlefier and E. Stackebrandt, "Molecular Systematics of Prokaryotes," Annual Review of Microbiology, Vol. 37, 1983, pp. 143-187. doi:10.1146/annurev.mi.37.100183.001043

[4] M. Langer, R. Wittner, P. Jack, H. Godel and H. Bruckner, "Strategies for Food Quality Control and Analytical Methods in Europe," In: W. Baltes, T. Eklund, R. Fenwick, W. Pfannhauser, A. Ruiter and H. P. Their, Eds., Proceedings of the 6th European Conference on Food Chemistry, Hamburg, 22-26 September 1991, pp. 385390.

[5] S. Ohtani and K. Yamamoto, "Age Estimation Using the
Racemization of Amino Acid in Human Dentin," Journal of Forensic Sciences, Vol. 36, No. 3, 1991, pp. 792-800.

[6] V. R. Meyer, "Chiral Separations by Liquid Chromatography," In: S. Ahuja, Ed., ACS Symposium Series, American Chemical Society, Washington DC, Vol. 471, 1991, pp. 217-227. doi:10.1021/bk-1991-0471.ch013

[7] V. A. Davankov, "Resolution of Racemates by Ligand Exchange-Exchange Chromatography," Advances in Chromatography, Vol. 18, 1980, pp. 139-142.

[8] Y. Tapuhi, N. Miller and B. L. Karger, "Practical Considerations in the Chiral Separation of DNS-Amino Acids by Reversed-Phase Liquid Chromatography Using Metal Chelated Additives," Journal of Chromatography A, Vol. 205, No. 2, 1981, pp. 325-337. doi:10.1016/S0021-9673(00)82660-6

[9] N. Oi, H. Kitahara and R. Kira, "Direct Separation of Enatiomers by High-Performance Liquid Chromatography on a New Chiral Ligand-Exchange Phase," Journal of Chromatography A, Vol. 592, No. 1-2, 1992, pp. 291296. doi:10.1016/0021-9673(92)85098-E

[10] S. Lam, F. Chow and A. Karmen, "Reversed-Phase HighPerformance Liquid Chromatographic Resolution of Dand D-DNS-Amino Acids by Mixed Chelate Complexation," Journal of Chromatography A, Vol. 199, 1980, pp. 295-305. doi:10.1016/S0021-9673(01)91381-0

[11] W. L. Hinze, T. E. Riehl, D. W. Armstrong, E. De Mond, A. Alak and T.Ward, "Liquid Chromatographic Separation of Enantiomers Using a Chiral, $\beta$-CyclodextrinBonded Stationary Phase and Conventional AqueousOrganic Mobile Phases," Analytical Chemistry, Vol. 57, No. 1, 1985, pp. 237-242. doi:10.1021/ac00279a055

[12] S. Li and W. C. Purdy, "From Inclusion Chemistry to Water Purifying Technology," Journal of Chromatography A, Vol. 543, No. 1, 1991, pp. 105-112. doi:10.1016/S0021-9673(01)95758-9

[13] N. Thuaud, B. Sebille, A. Deratani and G. Lelievre, "Retention Behavior and Chiral Recognition of $\beta$-Cyclodextrin Derivative Polymer Adsorbed on Silica for Warfarin, Structurally Related Compounds and DNS-Amino Acids," Journal of Chromatography A, Vol. 555, No. 1-2, 1991, pp. 53-64. doi:10.1016/S0021-9673(01)87166-1

[14] S. H. Lee, A. Berthod and D. W. Armstrong, "Systematic Study on the Resolution of Derivatized Amino Acids Enantiomers on Different Cyclodextrin-Bonded Stationary Phases," Journal of Chromatography A, Vol. 603, No. 1-2, 1992, pp. 83-93. doi:10.1016/0021-9673(92)85348-W

[15] J. Zukowska, M. Pawlowska and D. W. Armstrong, "Efficient Enantioselective Separation and Determination of Trace Impurities in Secondary Amino Acids (i.e., Imino Acids)," Journal of Chromatography A, Vol. 623, No. 1, 1992, pp. 33-41. doi:10.1016/0021-9673(92)85295-5

[16] M. Pawlowska, S. Chen and D. W. Armstrong, "Enantiomeric Separation of Fluorescent, 6-Aminoquinolyl-Nhydroxysuccinimidyl Carbamate, Tagged Amino Acids," Journal of Chromatography A, Vol. 641, No. 2, 1993, pp. 257-265. doi:10.1016/0021-9673(93)80142-U

[17] G. Crini, S. Bertini, G. Torri, A. Naggi, D. Sforzini, C. Vecchi, L. Lanus, Y. Lekchiri and M. Morcellet, "Sorp- 
tion of Aromatic Compounds in Water Using Insoluble Cyclodextrin Polymers," Journal of Applied Polymer Science, Vol. 68, No. 12, 1998, pp. 1973-1978. doi:10.1002/(SICI)1097-4628(19980620)68:12<1973::AI D-APP11>3.0.CO;2-T

[18] G. Crini, L. Janus, M. Morcellet, G. Torri, A. Naggi, S. Bertini and C. Vecchi, "Macroporous Polyamines Containing Cyclodextrin: Synthesis, Characterization, and Sorption Properties," Journal of Applied Polymer Science, Vol. 69, No. 7, 1998, pp. 1419-1427. doi:10.1002/(SICI)1097-4628(19980815)69:7<1419::AID -APP17>3.0.CO;2-O

[19] D. Li and M. Ma, "Nanosponges: From Inclusion Chemistry to Water Purifying Technology," Clean Products and Processes, Vol. 2, No. 2, 2000, pp. 112-116.

[20] M. Ma and D. Li, "New Organic Nanoporous Polymers and Their Inclusion Complexes," Chemistry of Materials, Vol. 11, No. 4, 1999, pp. 872-874.

doi:10.1021/cm981090y

[21] M. V. Rekharsky and Y. Inoue, "Complexation Thermodynamics of Cyclodextrins," Chemical Reviews, Vol. 98, No. 5, 1998, pp. 1875-1918. doi:10.1021/cr970015o

[22] D. Doulia, F. Rigas and C. Gimouhopoulos, "Removal of Amino Acids from Water by Adsorption on Polystyrene Resins," Journal of Chemical Technology \& Biotechnology, Vol. 76, No. 1, 2001, pp. 83-89. doi:10.1002/1097-4660(200101)76:1<83::AID-JCTB345 $>3.0 . \mathrm{CO} ; 2-\mathrm{N}$

[23] M. D. Saikia, "Studies on Adsorption of Amino Acids on $\beta$-Cyclodextrin Bonded to Silica Particles," Colloids and Surfaces A, Vol. 329, No. 3, 2008, pp. 177-183. doi:10.1016/i.colsurfa.2008.07.007

[24] S. Tang, L. Kong, J. Ou, Y. Liu, X. Li and H. Zou, “Application of Cross-Linked Beta-Cyclodextrin Polymer for Adsorption of Aromatic Amino Acids," Journal of Molecular Recognition, Vol. 19, No.1, 2006, pp. 39-48. doi:10.1002/jmr.756

[25] A. Banik, P. Gogoi and M. D. Saikia, "Interaction of Naproxen with $\beta$-Cyclodextrin and Its Derivatives/Polymer: Experimental and Molecular Modeling Studies," Journal of Inclusion Phenomena and Macrocyclic Chemistry, Vol. 72, No. 3-4, 2011, pp. 449-458. doi:10.1007/s10847-011-0014-7

[26] M. Dutta, R. Baruah, N. N. Dutta and A. C. Ghosh, "The Adsorption of Certain Semisynthetic Cephalosporins on Activated Carbon," Colloids and Surfaces A, Vol. 127, No. 1-3, 1997, pp. 25-37. doi:10.1016/S0927-7757(97)00062-9

[27] M. J. Frisch, G. W. Trucks, H. B. Schlegel, G. E. Scuseria, M. A. Robb, J. R. Cheeseman, G. Scalmani, V. Barons, B. Mennucci, G. A. Peterson, H. Nakatsuji, M. Li, Y. Carcicato, H. P. Hratchian, A. Izmaylov, J. Bloino, G. Zheng, J. L. Sonnenberg, M. Hada, M. Ehara, K. Toyota, R. Fukuda, J. Hasegawa, M. Ishida, T. Nakajima, Y. Honda, O. Kitao, H. Nakai, T. Vreven, J. A. Montgomery Jr., J. E. Peratta, F. Ogliaro, M. Bearpark, J. J. Heyd, E. Brothers, N. Kudin, V. N. Staroveroy, T. Keith, R. Kobayashi, J. Normand, K. Raghavachari, A. Rendell, J. C. Burant, S. S. Iyengar, J. Tomasi, M. Cossi, N. Rega, J. M. Millan, M.
Klene, J. E. Knox, J. B. Cross, V. Bakken, C. Adamo, J. Jarmillo, R. Gomperts, R. E. Stratmann, O. Yazev, A. J. Austin, R. Cammi, C. Pommeli, J. W. Ochierski, R. L. Martin, K. Morokuma, V. G. Zakrzewski, G. A. Voth, P.Salvador, J. J. Dannenberg, S. Dapprich, A. D. Daniels, O. Farkas, J. B. Foresman, J. V. Ortiz, J. Ciolowski and D. J. Fox, "Gaussian 09, Revision B.01," Gaussian, Inc., Wallingford, 2010.

[28] G. Piel, G. Dive, B. Evrard, T. Van Hees, S. H. de Hassonville and L. Delattre, "Molecular Modeling Study of Beta- and Gamma-Cyclodextrin Complexes with Miconazole," European Journal of Pharmaceutical Sciences, Vol. 13, No. 3, 2001, pp. 271-279. doi:10.1016/S0928-0987(01)00113-0

[29] M. Dutta, N. N. Dutta and K. G. Bhattacharya, "Aqueous Phase Adsorption of Certain Beta-Lactam Antibiotics onto Polymeric Resins and Activated Carbon," Separation and Purification Technology, Vol. 16, No. 3, 1999, pp. 213-224. doi:10.1016/S1383-5866(99)00011-8

[30] M. V. Chaubal, G. F. Payne, C. H. Reynolds and R. L. Albright, "Equilibria for the Adsorption of Antibiotics onto Neutral Polymeric Sorbents: Experimental and Modeling Studies," Biotechnology and Bioengineering, Vol. 47, No. 2, 1995, pp. 215-226. doi:10.1002/bit.260470213

[31] F. Salto and J. G. Prieto, "Interactions of and Penicillins with Nonpolar Macroporous Styrenedivinylbenzene Copolymers," Journal of Pharmaceutical Sciences, Vol. 70, No. 9, 1981, pp. 994-998. doi:10.1002/jps.2600700906

[32] Y. Nozaki and C. Tanford, "The Solubility of Amino Acids and Two Glycine Peptides in Aqueous Ethanol and Dioxane Solutions. Establishment of a hydrophobicity Scale," The Journal of Biological Chemistry, Vol. 246, No. 7, 1971, pp. 2211-2217.

[33] A. Romo, F. J. Penas and J. R. Isasi, "Sorption of Dibenzofuran Derivatives from Aqueous Solutions by $\beta$-Cyclodextrin Polymers: An Isosteric Heat Approach," Journal of Colloid and Interface Science, Vol. 279, No. 1, 2004, pp. 55-60. doi:10.1016/j.jcis.2004.06.043

[34] Y. S. Ho and G. McKay, "Pseudo-Second Order Model for Sorption Processes," Process Biochemistry, Vol. 34, No. 5, 1999, pp. 451-465. doi:10.1016/S0032-9592(98)00112-5

[35] K. Kano and H. Hasegawa, "Chiral Recognition of Helical Metal Complexes by Modified Cyclodextrins," Journal of the American Chemical Society, Vol. 123, No. 43, 2001, pp. 10616-10627. doi:10.1021/ja0112644

[36] H. A. Benesi and J. H. Hildebrand, "A Spectrophotometric Investigation of the Interaction of Iodine with Aromatic Hydrocarbons," Journal of the American Chemical Society, Vol. 71, No. 8, 1949, pp. 2703-2707. doi: $10.1021 / \mathrm{ja} 01176 \mathrm{a} 030$

[37] L. X. Song, H. M. Wang, P. Xu, Z. Q. Zhang and Q. Q. Liu, "Formation, Structure, and Stability of $\alpha$ - and $\beta$ Cyclodextrin Inclusion Complexes of Phenol and Benzoic Acid Derivatives in Vacuo and in Water," Bulletin of the Chemical Society of Japan, Vol. 80, No. 12, 2007, pp. 2313-2322. doi:10.1246/bcsj.80.2313

[38] Y. J. Cao, X. H. Xiao, R. H. Lu and Q. X. Guo, “1 H NMR 
Titration and Quantum Calculation for the Inclusion Complexes of Styrene and $\alpha$-Methyl Styrene with $\alpha, \beta$ and $\gamma$-Cyclodextrins," Journal of Molecular Structure, Vol. 660, No. 1-3, 2003, pp. 73-80.

doi:10.1016/j.molstruc.2003.07.011
[39] L. Liu and X. Guo, "Use of Quantum Chemical Methods to Study Cyclodextrin Chemistry," Journal of Inclusion Phenomena and Macrocyclic Chemistry, Vol. 50, No. 1-2, 2004, pp. 95-103. doi:10.1007/s10847-003-8847-3 


\section{Supplementary Information}

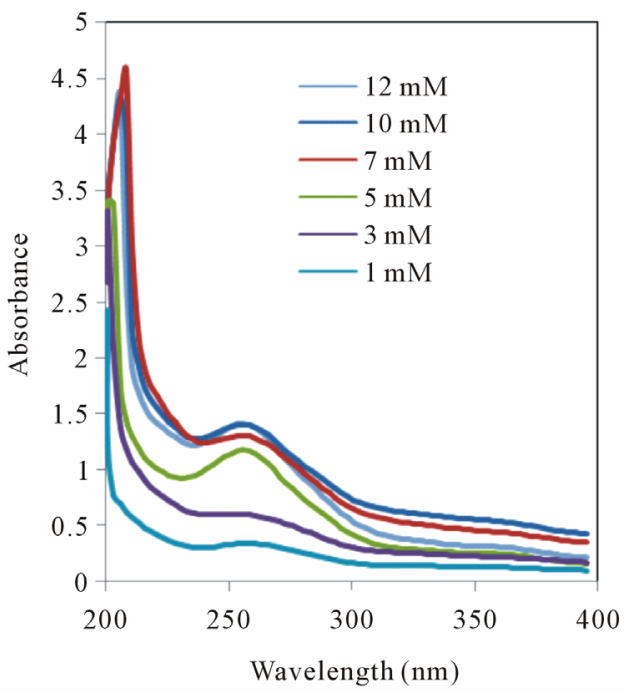

(a)

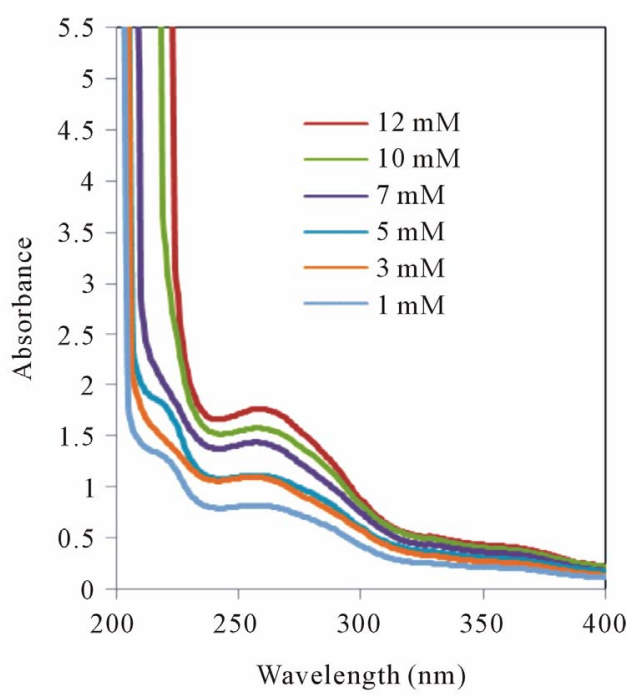

(b)

Figure S1. UV absorption spectra of (a) L-Tryptophan and (b) D-Tryptophan in presence of various concentration of $\beta$-CD.

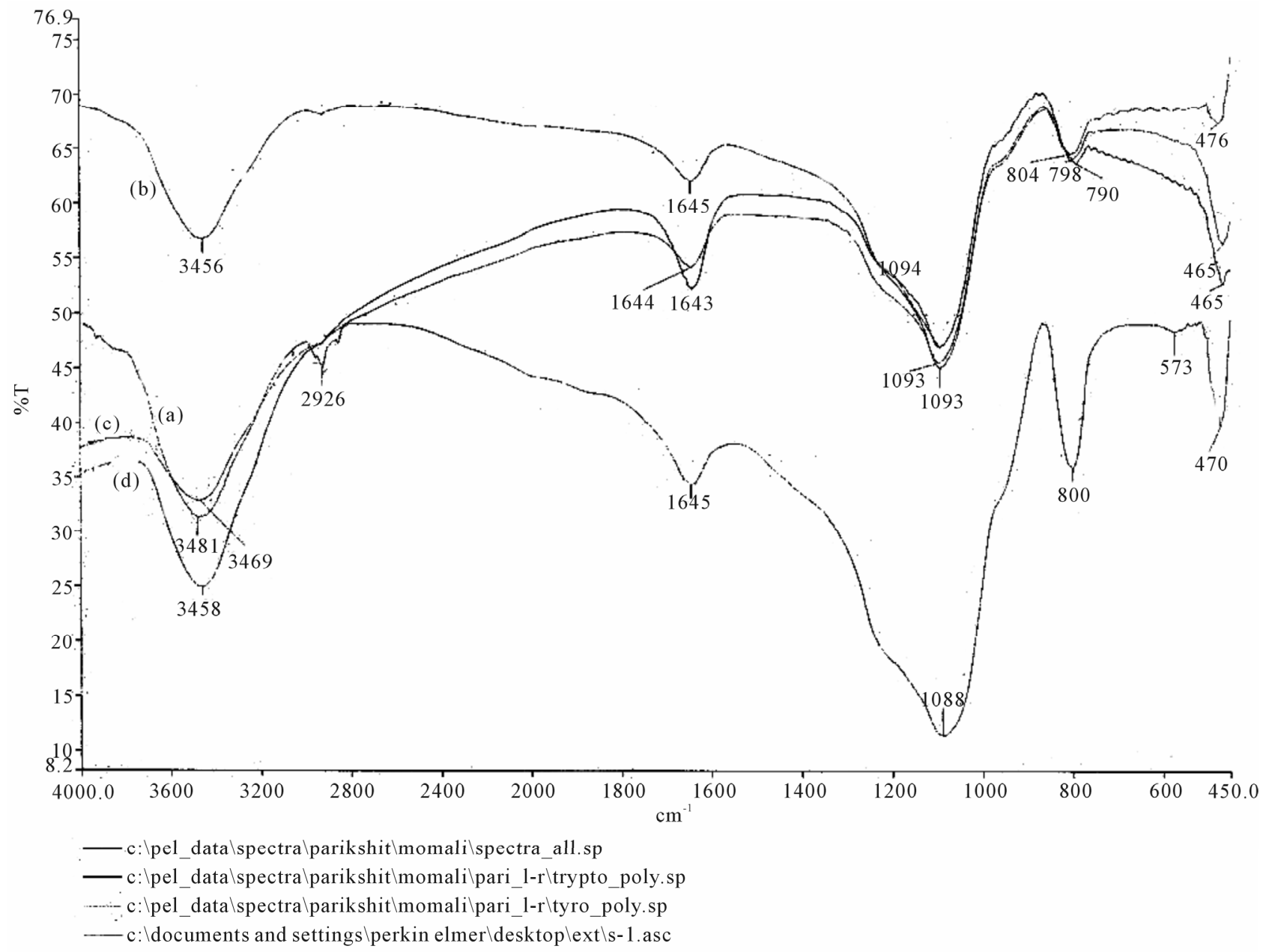

Figure S2. FTIR spectra of (a) CDS; (b) L-tryptophan loaded on CDS; (c) L-phenylalanine loaded on CDS and (d) L-tyrosine loaded on CDS. 


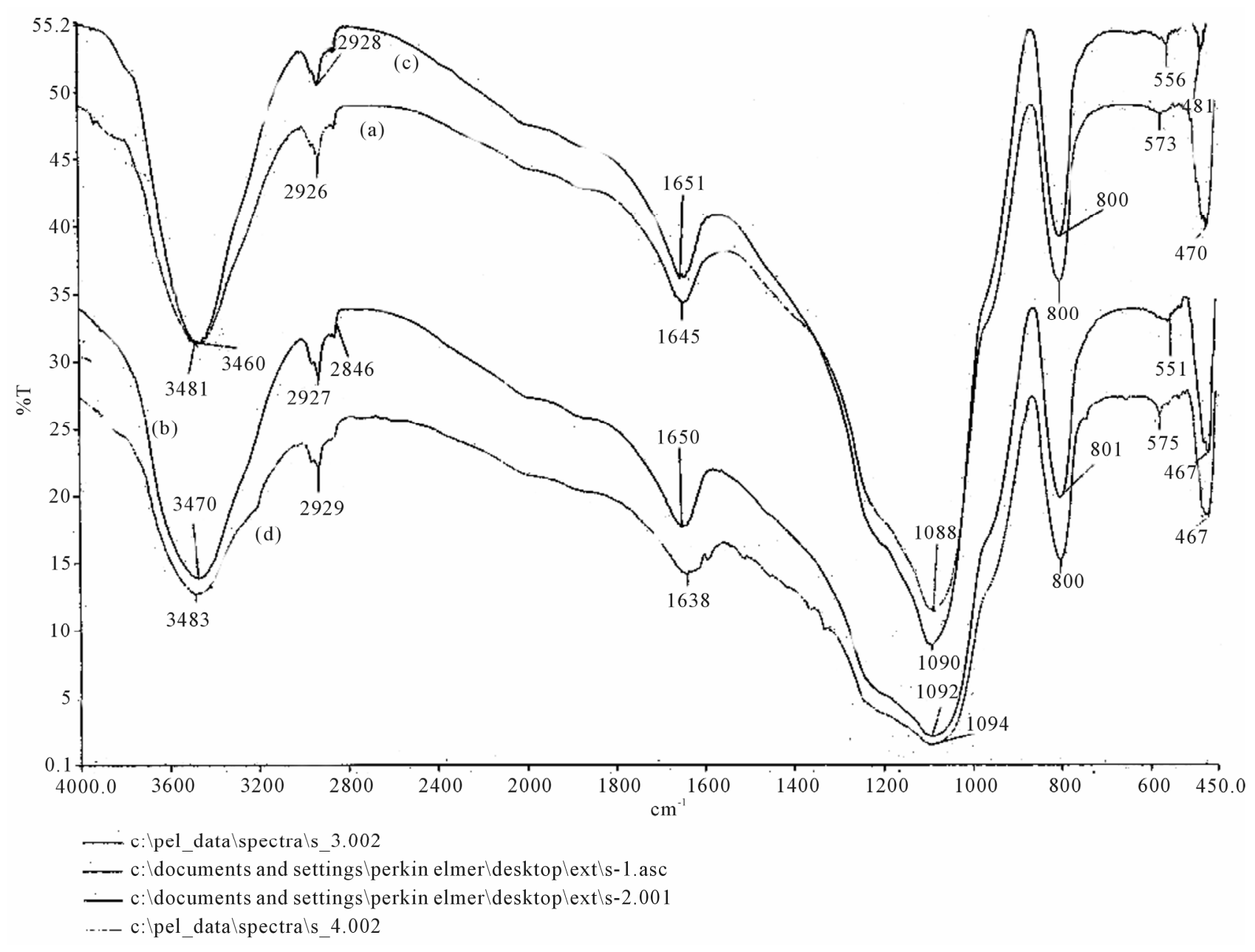

Figure S3. FTIR spectra of (a) CDS; (b) D-tryptophan loaded on CDS; (c) D-phenylalanine loaded on CDS and (d) D-tyrosine loaded on CDS. 